13

\title{
Ионно-пучковые методики прецизионной обработки оптических поверхностей
}

\author{
(С) И.Г. Забродин, М.В. Зорина, И.А. Каськов, И.В. Малышев, М.С. Михайленко, А.Е. Пестов, \\ Н.Н. Салащенко, А.К. Чернышев, Н.И. Чхало
}

Институт фризики микроструктур РАН, 607680 Нижний Новгород, Россия

I e-mail: aepestov@ipm.sci-nnov.ru

Поступило в Редакцию 3 апреля 2020 г.

В окончательной редакции 3 апреля 2020 г.

Принято к публикации 3 апреля 2020 г.

Описаны методики прецизионной обработки поверхности оптических элементов пучками ускоренных ионов. Приведены характеристики и возможности оборудования, а также решаемые с помощью него задачи. Подробно описаны возможности финишной коррекции локальных ошибок формы малоразмерным ионным пучком, осесимметричной коррекции/асферизации широкоапертурным сильноточным ионным пучком и ионной полировки. Представлены значения эффективной шероховатости поверхности плавленого кварца, ситалла, Zerodur'a, ULE® в диапазоне пространственных частот $q \in\left[2.5 \cdot 10^{-2}-6.0 \cdot 10^{1} \mu \mathrm{m}^{-1}\right]$, а также примеры формирования сферической поверхности и профиля асферизации.

Ключевые слова: ионно-пучковая методика, пучок ускорения, кварц, ситалл.

DOI: 10.21883/JTF.2020.11.49985.112-20

\section{Введение}

Развитие современных технологий, науки и техники требует повышения качества оптических элементов и оптических систем в целом. За последние 10 лет требования к точности формы и шероховатости поверхности перешли в субнанометровую область. В первую очередь это связано с переходом в коротковолновый диапазон длин волн: от вакуумного ультрафиолетового (ВУФ, длины волн $100-200 \mathrm{~nm}$ ) до экстремального ультрафиолетового (ЭУФ, длины волн $10-100 \mathrm{~nm}$ ) и даже мягкого рентгеновского (МР, длины волн 3-10 nm). Здесь появляется все больше как научных задач, связанных, например, с изучением физики Солнца и верхних слоев атмосферы [1], так и прикладных, таких, как системы мониторинга околоземного пространства в ВУФ [2]. Активно развиваются технологии создания микроэлектроники посредством ЭУФ нанолитографии [3], а также разрабатываются методики нанодиагностики на основе микроскопии в области „водяного окна“ (длины волн $2.4-4 \mathrm{~nm})[4]$.

В этих областях спектра электромагнитного излучения значительное влияние оказывает поглощение, в связи с чем здесь невозможна преломляющая оптика, т.е. разработчики вынуждены использовать только зеркальные оптические элементы. Очевидно, что для рентгеновского диапазона есть область полного внешнего отражения, при углах падения излучения меньше критического, которая позволяет обеспечить близкий к единице коэффициент отражения, однако построение прецизионной изображающей оптики на элементах скользящего падения невозможно в силу значительных сферических аберраций при существенно неосевом падении излучения на поверхность и низких числовых апертур оптических элементов. Следовательно, необходимо создание элементов нормального падения, что в этой области длин волн возможно только с применением многослойных интерференционных структур, коэффициенты отражения которых на рабочих длинах волн, могут достигать десятков процентов. Тем не менее это существенно отличается от единицы, и если в преломляющей оптике решение таких проблем, как расширение поля зрения оптических систем, удается решать с помощью многолинзовых объективов, каждый элемент которого при этом является сферическим, то в случае МР и ЭУФ излучения из-за низкого отражения необходимо минимизировать число элементов. Соответственно, чтобы получить изображение дифракционного качества в широком поле зрения, элементы объектива должны стать асферическими, причем зачастую это очень сложная асферика четвертого, шестого и даже более высоких порядков. Это существенно усложняет их изготовление. Кроме того, для приближения к теоретическому пределу коэффициента отражения, помимо качества самой многослойной структуры, существенное значение имеет шероховатость подложки, оказывающая значительное влияние на межслойную шероховатость структуры, и, как следствие, на величину коэффициента отражения. Поэтому задача развития новых методов обработки оптических поверхностей, сочетающих в себе высокую точность съема материала, позитивное влияние на шероховатость, высокую производительность и низкую стоимость технологического процесса, является крайне актуальной. 
В наибольшей степени этим требованиям удовлетворяет ионно-пучковое травление [5-8]. Это бесконтактный метод обработки поверхности, основанный на физическом явлении распыления материала с поверхности под воздействием ионной бомбардировки. Данный метод позволяет контролируемо удалять материал с субнанометровой точностью. Активно он стал применяться примерно с конца 80-х, начала 90-х годов прошлого столетия [9-11]. В настоящее время на мировом рынке и в лабораториях имеется большое количество машин, производящих обработку поверхности оптических элементов пучком ускоренных ионов [12-15]. Все приведенные выше установки реализованы по одному принципу: источник ускоренных ионов установлен на манипулятор и при обработке поверхности производится сканирование источником вдоль поверхности детали. Отличия заключаются лишь в количестве степеней свободы перемещения источника, что ограничивает класс решаемых с помощью установки задач.

В настоящей работе машина ионно-пучковой обработки оптических поверхностей реализована по иному принципу. Здесь реализована концепция подвижной детали, т.е. на гониометр с пятью степенями свободы устанавливается образец. Данное решение позволило соединить в одной установке все методики ионнопучковой обработки поверхности, а именно полировка и асферизация сильноточным широкоапертурным пучком ионов и коррекция локальных ошибок формы малоразмерным ионным пучком. При необходимости произвести заданную операцию подложка просто поворачивается в направлении нужного источника. Кроме того, данная концепция позволяет проводить последовательную обработку несколькими источниками без развакуумирования, что востребовано при решении ряда задач, например, при обработке металлов, где на поверхности всегда есть слой окисла, или при проведении предварительной чистки поверхности от пленок углеводородов в кислородной плазме. Также гониометр позволяет проводить обработку любых поверхностей (вогнутых/выпуклых), обеспечивая локальную нормаль или другие произвольные углы падения.

\section{1. Установка ионно-пучкового травления}

Bce методики прецизионной обработки оптических поверхностей реализованы на установке ионнопучкового травления, подробное описание которой приведено в работе [16]. Установка оснащена тремя технологическими источниками ускоренных ионов, работающих с инертными и активными газами в диапазоне энергий $50-1500 \mathrm{eV}$. Два источника с квазипараллельным ионным пучком и выходными апертурами КЛАН-103М эллипс $60 \times 90 \mathrm{~mm}$ и КЛАН-163М - Ø $150 \mathrm{~mm}$ соответственно. Третий источник - с фокусировкой ионного пучка. За счет вогнутых сеток на расстоянии $70 \mathrm{~mm}$

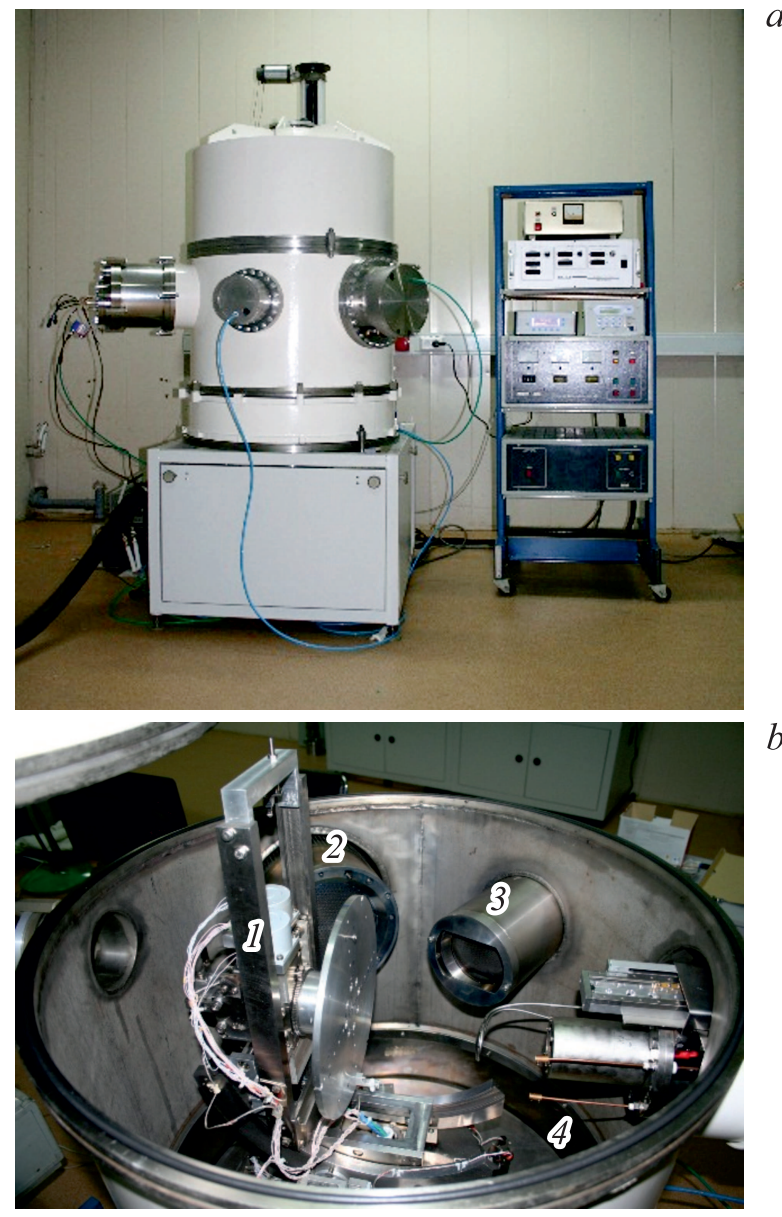

Рис. 1. Фото установки ионно-пучкового травления; $a$ - внешний вид со стойкой управления, $b-$ вид изнутри: 1 - гониометр, 2 - КЛАН-163М, 3 - КЛАН-103М, 4 - фокусирующий источник с водоохлаждаемой диафрагмой.

от выходной апертуры пучок сжимается до $15 \mathrm{~mm}$ в диаметре. За счет дополнительных водоохлаждаемых диафрагм, устанавливаемых в область перетяжки, выходной пучок может быть уменьшен до $1 \mathrm{~mm}$. Фото установки на рис. 1.

Широкоапертурные источники с квазипараллельным ионным пучком позволяют проводить асферизацию поверхности через формирующую диафрагму, а источник с фокусировкой ионного пучка предназначен для проведения локальной коррекции формы малоразмерным пучком ускоренных ионов. Для работы с диэлектрическими материалами применяется дополнительный термокатоднейтрализатор, установленный на выходе каждого ионного источника, он позволяет полностью скомпенсировать заряд ионного пучка и проводить травление нейтрализованными ионами. Очевидно, что стабильность работы источников является важным условием для реализации прецизионных методик обработки оптических поверхностей. В работе [16] приведены технологические параметры всех источников, в частности разброс ионов по энергии, который по данным производителей не 
превышает $\pm 3 \mathrm{eV}$. Для поддержания стабильного во времени значения тока ионов в программе управления установкой реализована обратная связь, поддерживающая ток ионов за счет тока на катоде с точностью $\pm 0.1 \mathrm{~mA}$.

Как можно видеть на фото (рис. 1,b), источники жестко закреплены на корпусе установки, а сканирование ионным пучком вдоль обрабатываемой поверхности осуществляется за счет перемещения детали, которая устанавливается на столик гониометра.

Гониометр - пятикоординатный моторизованный столик, подробное описание которого представлено в работе [16], позволяет перемещать образец вдоль следующих осей. Ось $\omega$ - центральное вращение образца; ось $X$ - перемещение вдоль оси вращения образца; ось $Z$ - перемещение по вертикали (перпендикулярно оси вращения образца); ось $\varphi-$ наклон образца (поворот вокруг оси $Y$, перпендикулярной осям $X$ и $Z$ ); ось $\psi$ выбор ионного источника (поворот вокруг оси $Z$ ). Bсе перечисленные выше оси пересекаются в одной точке центре гониометра. На шестую моторизованную подвижку поставлена заслонка (на фото не представлена), отделяющая источник от рабочего объема камеры, заслонка также служит измерителем ионного тока. Включение источника и выход на его рабочие параметры осуществляется при закрытой заслонке, перед началом процесса обработки заслонка открывается.

\section{2. Распределение ионного тока по апертуре источника}

Проведение прецизионной обработки поверхности оптических элементов предполагает достоверное определение распределения тока ионов по апертуре каждого ионного источника в плоскости, перпендикулярной оси источника и проходящей через центр гониометра.

\section{1. Фокусирующий источник}

Источник $(4$, рис. $1, b)$ оснащен фокусирующей ионнооптической системой за счет применения вогнутых ускоряющей и формирующей сеток. Первоначально определялось положение области фокусировки ионного пучка, для этого измерялось сечение пучка ионов в зависимости от расстояния от выходной апертуры (рис. 2). Измерения проводились с помощью цилиндра Фарадея с входной апертурой $\varnothing 1 \mathrm{~mm}$.

Ширина пучка на полувысоте в области „перетяжки“ составила $14.7 \mathrm{~mm}$, что обеспечивает плотность ионного тока в области фокусировки на уровне $6.0 \mathrm{~mA} / \mathrm{cm}^{2}$ при токе ионного пучка $10 \mathrm{~mA}$. Для получения требуемого размера ионного пучка в область „перетяжки“ устанавливается водоохлаждаемая диафрагма с отверстием нужного диаметра. На рис. 3 приведен кратер, сформированный на кварцевой пластине через диафрагму Ø $2 \mathrm{~mm}$.

Кратер измерялся на широкопольном интерферометре белого света Zygo New View 5022. Аналогичные зави-

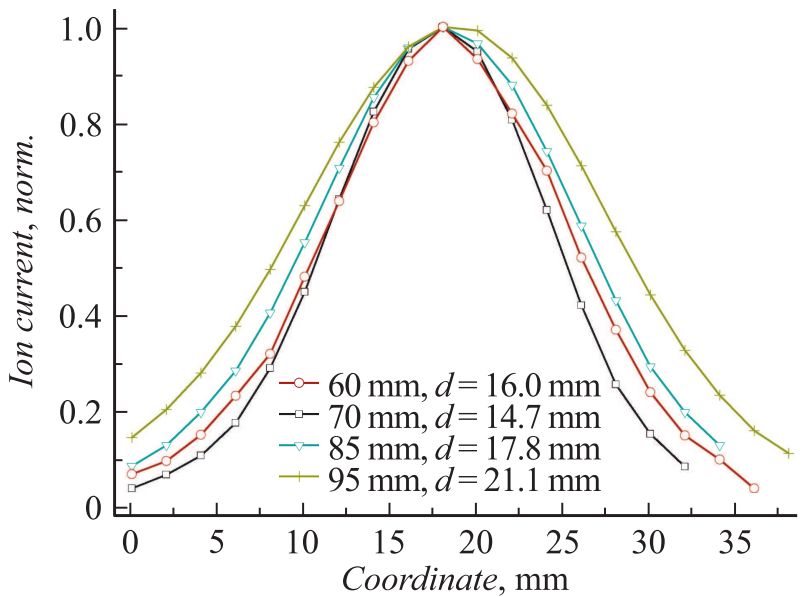

Рис. 2. Сечения ионного пучка в зависимости от расстояния до выходной апертуры.

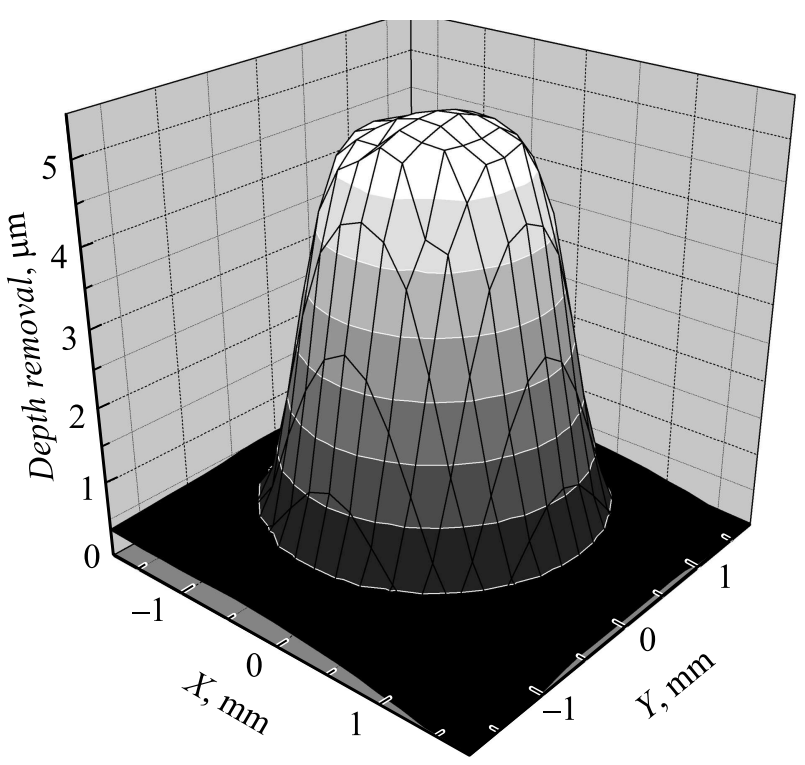

Рис. 3. Кратер, сформированный в пластине $\mathrm{SiO}_{2}$ после $2 \mathrm{~mm}$ диафрагмы на расстоянии $4 \mathrm{~mm}$ от водоохлаждаемой диафрагмы. Газ Ar, $I_{\text {ion }}=10 \mathrm{~mA}$.

симости снимались для всей номенклатуры диафрагм $(1,2,4,6,10 \mathrm{~mm})$. Полученные распределения скорости травления от координаты впоследствии использовались для расчета карты травления для процедуры коррекции локальных ошибок формы.

Два других источника (2 и 3 , рис. $1, b)$ имеют плоскую ионно-оптическую систему и соответственно квазипараллельный пучок ионов.

\section{2. Источник с горячим катодом}

Источник (3, рис. 1,b) имеет тип Кауфман КЛАН-103М (НТК „Платар“). Выходная апертура источника представляет собой эллипс с полуосями 45 и $30 \mathrm{~mm}$. Источник с горячим катодом позволяет в том 

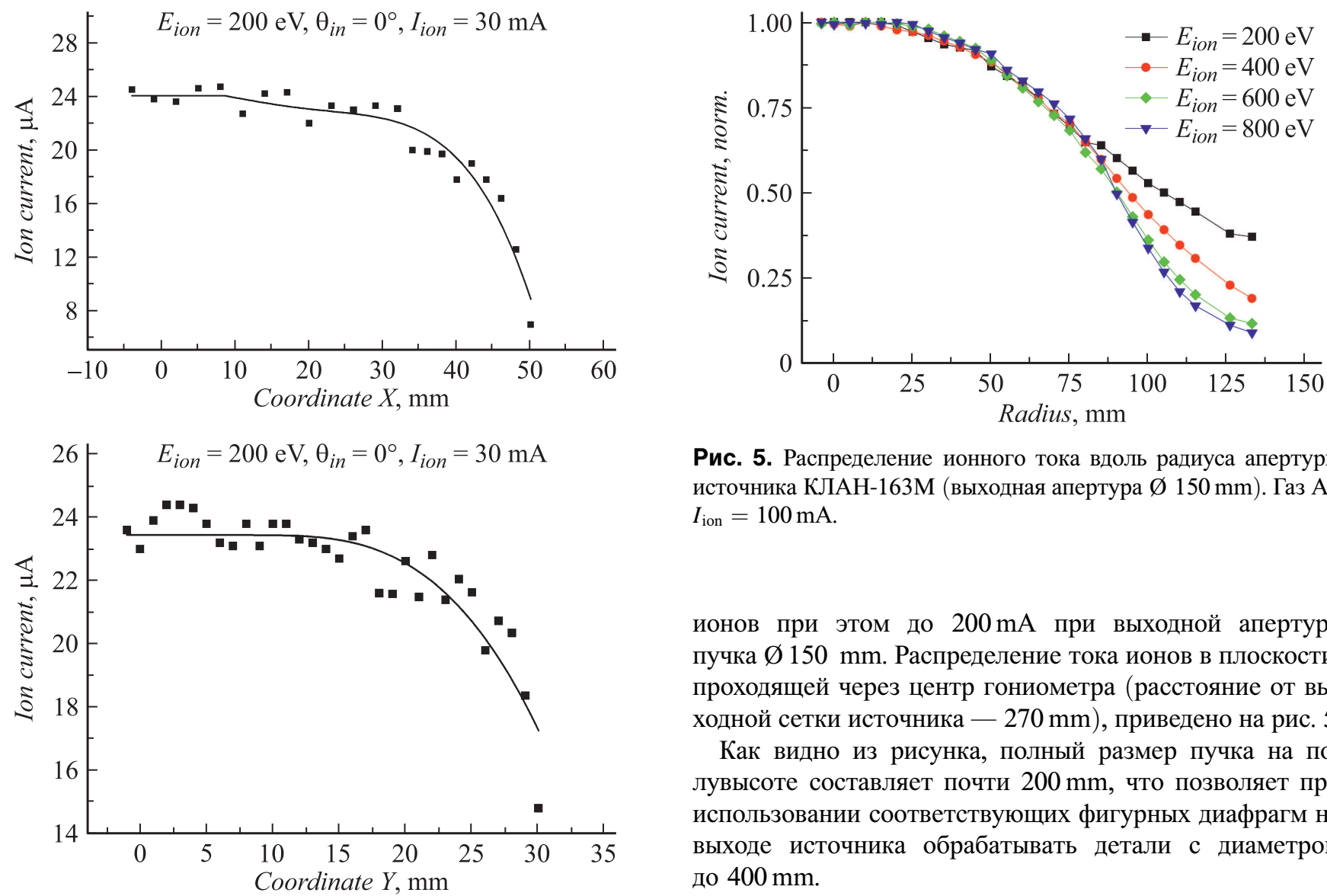

Рис. 5. Распределение ионного тока вдоль радиуса апертуры источника КЛАН-163М (выходная апертура Ø $150 \mathrm{~mm}$ ). Газ Ar, $I_{\text {ion }}=100 \mathrm{~mA}$.

ионов при этом до $200 \mathrm{~mA}$ при выходной апертуре пучка $\varnothing 150 \mathrm{~mm}$. Распределение тока ионов в плоскости, проходящей через центр гониометра (расстояние от выходной сетки источника $-270 \mathrm{~mm}$ ), приведено на рис. 5 .

Как видно из рисунка, полный размер пучка на полувысоте составляет почти $200 \mathrm{~mm}$, что позволяет при использовании соответствующих фигурных диафрагм на выходе источника обрабатывать детали с диаметром до $400 \mathrm{~mm}$.

Рис. 4. Распределение ионного тока вдоль апертуры источника КЛАН-103М (выходная апертура - эллипс $90 \times 60 \mathrm{~mm}$ ). Газ $\mathrm{Ar}, I_{\text {ion }}=30 \mathrm{~mA}$.

числе решать ряд задач, где требуются либо большие давления рабочих газов (например, для водорода), либо низкие энергии ионов от $50 \mathrm{eV}$ (травление металлов без развития шероховатости).

Результаты измерений ионного тока в плоскости, перпендикулярной ионному пучку и проходящей через центр гониометра (расстояние от выходной апертуры $200 \mathrm{~mm}$ ), проведенных при помощи „цилиндра Фарадея“ с диаметром входного отверстия $2 \mathrm{~mm}$ в двух взаимно перпендикулярных направлениях, приведены на рис. 4. Нулевая координата соответствует центру пучка и центру гониометра.

Как можно видеть из кривых, представленных на рис. 4, наблюдается хорошая однородность ионного тока вдоль выходной апертуры источника.

\section{3. Радиочастотный источник}

Основные работы по ионной полировке и асферизации оптических поверхностей производятся с помощью сильноточного широкоапертурного радиочастотного источника КЛАН-163М (НТК „Платар“). Источник позволяет работать в диапазоне энергий ионов $200-1000 \mathrm{eV}$, ток

\section{3. Методики обработки}

Из всего класса методик финишной обработки оптических поверхностей ионно-пучковым травлением глобально можно выделить две основные - это осесимметричная и несимметричная. Осесимметричная обработка производится сильноточным источником с квазипараллельным пучком ускоренных ионов через формирующую диафрагму. Методика позволяет проводить большие съемы материала одновременно с больших площадей поверхности оптического элемента. Несимметричная обработка предполагает малые съемы материала из-за использования малоразмерного ионного пучка и применяется в основном для финишной коррекции локальных ошибок формы.

\section{1. Несимметричная обработка}

Наиболее сложной в реализации и требующей значительного времени является методика коррекции локальных ошибок формы малоразмерным ионным пучком. Основой данной методики является измерение формы поверхности оптической детали с помощью интерферометра с дифракционной волной сравнения (ИДВС) [17]. Изобретение уникального источника сферической волны - зауженного до субволновых размеров оптоволокна $[18]-$ позволило построить на его основе прибор, обеспечивающий волновые аберрации сферических 
фронтов на уровне единиц ангстрем $(\mathrm{RMS}<0.3 \mathrm{~nm})$ в числовой апертуре NA $<0.3$. Главным достоинством прибора является отсутствие эталона, качество которого всегда вызывает сомнение.

Задача коррекции заключается в доведении исходной поверхности, изготовленной на механическом оптическом станке, до дифракционного качества. Для этого производится сканирование малоразмерным пучком ускоренных ионов вдоль поверхности с целью снижения амплитуды отклонения формы поверхности от расчетной.

Для решения данной задачи написана программа [19], моделирующая взаимодействие малоразмерного ионного пучка с поверхностью. Таким образом, на входе программа получает карту поверхности, полученную на ИДВС, и измеренное распределение ионного тока в пучке. Программа в отличие от предыдущей реализации, описанной в [16], не ставит в прямую зависимость время травления в точке от высоты отклонения формы поверхности в данной точке, а ищет такое положение пучка на поверхности, которое обеспечивает максимальное снижение RMS поверхности с учетом воздействия всех точек пучка. Т. е. задача решается не минимизаций функционала свертки двух поверхностей (пучка и поверхности), а перебором. Такой алгоритм заметно увеличивает время работы программы, однако позволяет, во-первых, существенно продвинуться в область более высоких пространственных частот, доступных для обработки [19], и, во-вторых, не приводит к формированию на поверхности детерминированных ошибок. Предыдущая реализация программы приводила к формированию на поверхности кольцевой структуры с характерным периодом порядка размера ионного пучка. Такая ошибка формы, даже с низким RMS, представляет собой сферическую аберрацию высокого порядка, которая приводит к снижению разрешающей способности оптической системы.

Таким образом, процедура коррекции представляет собой следующую последовательность действий. На под-

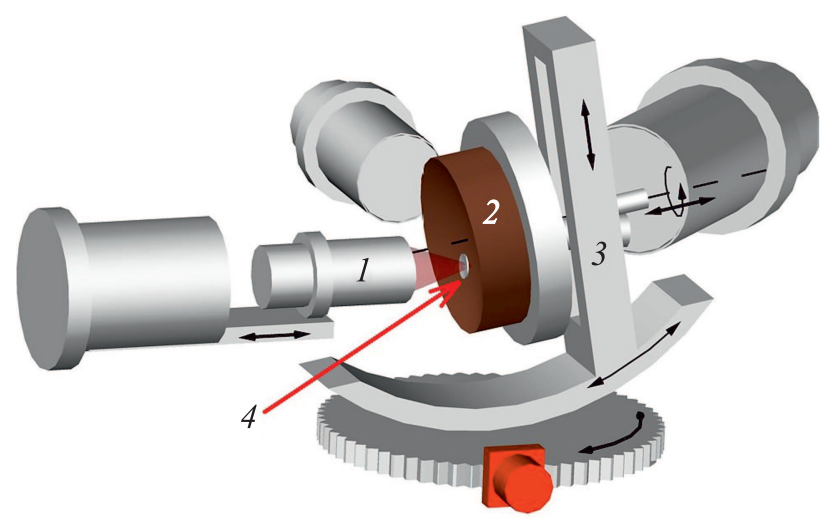

Pис. 6. Схема эксперимента по коррекции локальных ошибок формы: 1 - источник с фокусировкой ионного пучка; 2 - образец; 3 - пятиосный гониометр; 4 - обрезающая водоохлаждаемая диафрагма.
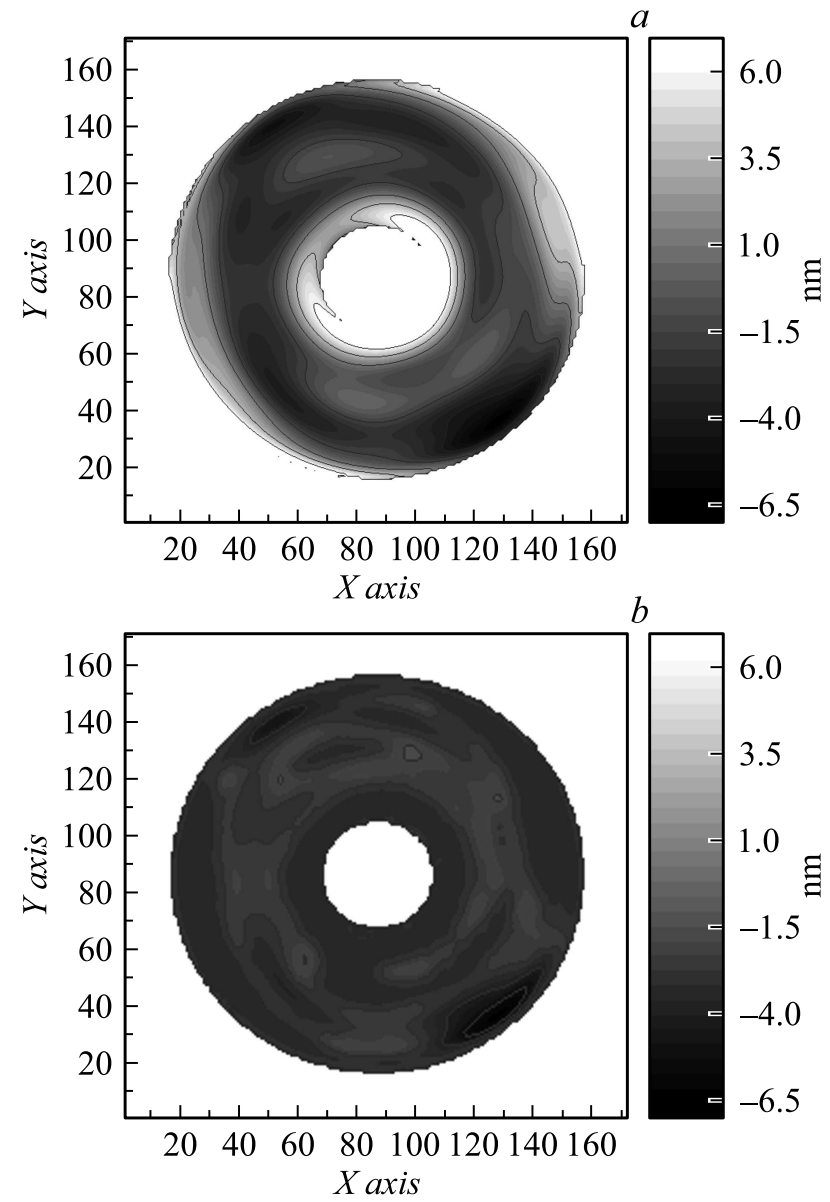

Рис. 7. Карта поверхности сферической детали диаметром $100 \mathrm{~mm}$ и радиусом кривизны $137.5 \mathrm{~mm}$, полученная с помощью ИДВС; $a-$ исходная $\mathrm{PV}=19.7 \mathrm{~nm}, \mathrm{RMS}=3.16 \mathrm{~nm}$; $b$ - после процедуры коррекции локальных ошибок формы $\mathrm{PV}=6.8 \mathrm{~nm}, \mathrm{RMS}=1.37 \mathrm{~nm}$.

готовительном этапе измеряется форма ионного пучка (рис. 3), затем с помощью интерферометра с дифракционной волной сравнения получается карта отклонения формы реальной поверхности от расчетной. Проводится расчет карты травления с помощью программы моделирования взаимодействия малоразмерного ионного пучка с поверхностью. По рассчитанной карте производится травление (рис. 6) таким образом, чтобы в каждой точке карты (для любых выпуклой/вогнутой деталей) обеспечивалась локальная нормаль к поверхности и постоянный зазор между обрезающей пучок диафрагмой и поверхностью. Затем вновь производится измерение формы поверхности на ИДВС.

Зачастую с уменышением амплитуды неоднородностей на поверхности проявляется более высокочастотный рельеф, что требует проведения коррекции с уменьшением размера ионного пучка. Для этого производится замена обрезающей диафрагмы (4, рис. 6). Описанная выше последовательность действий повторяется до тех пор, 
пока форма поверхности не удовлетворит требуемым параметрам.

Пример реализации процедуры коррекции локальных ошибок формы для сферической детали диаметром $100 \mathrm{~mm}$ и радиусом кривизны $137.5 \mathrm{~mm}$ представлен на рис. 7.

Как можно видеть, за одну итерацию форма поверхности по параметру RMS была улучшена почти в 2.5 раза - с исходных 3.16 до $1.37 \mathrm{~nm}$. Процедура коррекции производилась с помощью источника с фокусировкой ионного пучка, диаметр пучка после обрезающей диафрагмы составлял $4 \mathrm{~mm}$. „Чистое“ время процесса (без учета переездов) составило $2 \mathrm{~h} 15 \mathrm{~min}$. Сканирование осуществлялось путем вращения детали и перемещения вдоль оси $Z$ после каждого оборота. На каждом шаге производилась подстройка координат $X$ и $\varphi$ для поддержания локальной нормали к поверхности и заданного расстояния источник-образец. Суммарное время всего процесса с учетом перемещений составило около 4 часов.

Кроме вышеописанной процедуры коррекции локальных ошибок формы по карте отклонения высоты неоднородностей в зависимости от координаты, полученной с помощью ИДВС, применение методики ионно-пучковой обработки поверхности малоразмерным ионным пучком позволяет сформировать на поверхности произвольный профиль, например, синусоиду или концентрические кольца. В данном случае в качестве входных данных в программу моделирования следует загружать теоретически смоделированную поверхность, представляющую собой инвертированный требуемому профиль. Возможности методики по латеральным размерам и высоте ограничены минимальным размером пучка и скоростью травления.

\section{2. Осесимметричная обработка}

Осесимметричная обработка интересна для широкого класса задач, при которых необходимо проводить съем материала вдоль всей поверхности с некоторой детерминированной зависимостью глубины травления $(H)$ от радиуса детали (т.е. $H=H(r))$, в том числе $H(r)=\mathrm{const}$ (т. е. равномерный съем материала по поверхности).

Примером может служить асферизация поверхности. Асферизация поверхностей элементов изображающей оптики позволяет, например, расширить поле зрения проекционной схемы за счет компенсации сферических аберраций для внеосевых лучей. Механическая асферизация, особенно асферик высокого порядка, является сложной задачей, поскольку теряются все преимущества притира, т.е. контакта инструмента со всей поверхностью, приходится уменьшать инструмент, а это приводит к развитию среднечастотных неоднородностей, убирать которые очень сложная задача. Ионная асферизация лишена этих проблем.

Процедура осесимметричной обработки поверхности производится по схеме, представленной на рис. 8.

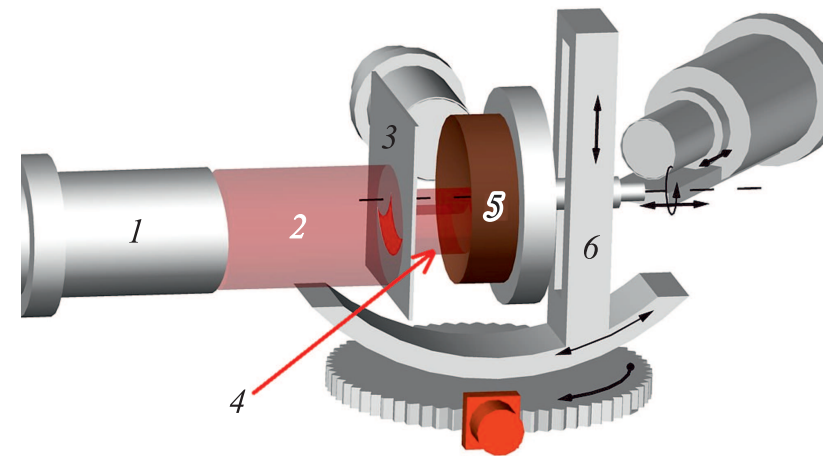

Рис. 8. Схема эксперимента по осесимметричной обработке поверхности: 1 - широкоапертурный источник ионов; 2 - квазипараллельный ионный пучок; 3 - формирующая диафрагма; 4 - ионный пучок после диафрагмы; 5 - образец; 6 - гониометр.

Данные по распылению материалов

\begin{tabular}{l|c|c|c}
\hline Материал & $E_{\text {ion }}, \mathrm{eV}$ & $Y$, atom/ion & $\sigma_{\text {eff, }} \mathrm{nm}$ \\
\hline $\mathrm{SiO}_{2}$ & 500 & 0.28 & 0.27 \\
Zerodur & 300 & 0.13 & 0.82 \\
ULE® & 800 & 0.4 & 0.28 \\
Ситалл & 300 & 0.15 & 0.32
\end{tabular}

Применение для этой задачи широкоапертурного сильноточного источника с квазипараллельным ионным пучком позволяет обрабатывать подложки диаметром до $300 \mathrm{~mm}$ со значительным съемом материала (единицы-десятки $\mu \mathrm{m}$ ). Например, в работе [20] была проведена асферизация оптической линзы со съемом материала в максимуме $34 \mu \mathrm{m}$.

Как можно видеть из рисунка, методика заключается в формировании осесиметричного профиля на поверхности вращающейся вокруг своей оси обрабатываемой детали при воздействии ионного пучка, сечение которого задано формирующей диафрагмой.

Так как для асферизации используется широкоапертурный сильноточный пучок, а обрабатываемые детали зачастую имеют сложную форму (выпуклая/вогнутая) поверхности, необходимо учитывать влияние локальных углов падения ионов на поверхность образца на шероховатость поверхности и скорость удаления материала. С этой целью был проведен ряд исследований влияния ионно-пучкового травления на распыление различных оптических материалов (плавленый кварц, $\mathrm{Si}$, оптические керамики типа Ситалл, Zerodur, ULE®, различные металлы) [21-23]. В таблице приведены сравнительные значения коэффициентов распыления $(Y)$ различных материалов и достигнутые в ходе исследований значения шероховатости, полученные на образцах, изготовленных по стандартной оптической технологии, с исходной шероховатостью на уровне $\sigma_{\text {eff }}=0.5 \mathrm{~nm}$ в диапазоне пространственных частот $q \in\left[2.5 \cdot 10^{-2}-6.0 \cdot 10^{1} \mu \mathrm{m}^{-1}\right]$. 
Как можно видеть из таблицы, наиболее перспективным с точки зрения применения в коротковолновой области материалом оказались плавленый кварц и ULE®. Ситалл также может быть применим для формирования оптических поверхностей, где съем материала предполагается менее $2 \mu \mathrm{m}$, поскольку при больших съемах материала наблюдается деградация поверхности [22]. Для образцов из Zerodur'a не было обнаружено параметров ионно-пучковой обработки, не приводящей к развитию шероховатости.

В ходе исследований было обнаружено, что скорость травления в зависимости от угла падения $\left(V_{\text {etch }}(\theta)\right)$ может изменяться в разы [24,25], что следует учитывать при расчете формирующей диафрагмы. Что касается шероховатости поверхности, минимальное значение которой важно в первую очередь для подложек многослойных зеркал МР и ЭУФ диапазонов длин волн, то зависимость от угла имеет сложную немонотонную зависимость [25]. Например, для плавленого кварца было показано, что при травлении нейтрализованными ионами $\mathrm{Ar}$ с энергией $E_{\text {ion }}=1250 \mathrm{eV}$ эффективная шероховатость остается на уровне $\sigma_{\text {eff }} \sim 0.25 \mathrm{~nm}$ в диапазоне пространственных частот $q \in\left[4.9 \cdot 10^{-2}-6.3 \cdot 10^{1} \mu \mathrm{m}^{-1}\right]$ при углах падения ионов $\theta_{\text {in }}=0-35^{\circ}$ от нормали [22], что соответствует числовой апертуре 0.6. Это означает, что образцы из плавленого кварца с числовой апертурой NA < 0.6 могут обрабатываться квазипараллельным ионным пучком с обеспечением шероховатости на уровне, приемлемом для подложек МР и ЭУФ диапазонов длин волн. Для металлических образцов на скорость распыления на начальной стадии существенное влияние оказывает наличие окисленного слоя, а шероховатость поверхности на уровне $\sigma_{\text {eff }} \sim 0.3 \mathrm{~nm}$ сохраняется при углах падения $\theta_{\text {in }}=0-30^{\circ}$ и минимальных энергиях ионов $\left(E_{\mathrm{ion}}=200-300 \mathrm{eV}\right)[26]$. В работе [27] проведено исследование возможностей ионно-пучковой обработки поверхности образцов из массивного бериллия, покрытых аморфной пленкой никеля. Показана возможность проведения глубокого травления (глубина до $250 \mathrm{~nm}$ ) без деградации исходной шероховатости, что может быть востребовано для асферизации.

С учетом всего вышесказанного можно описать алгоритм формирования заданного профиля на поверхности обрабатываемой детали. На начальном этапе производится расчет скорости травления в зависимости от радиуса детали $(\operatorname{Vetch}(\mathrm{r}))$ с учетом распределения ионного тока в пучке $(I(r)$, рис. 4 и 5) и локального угла падения ионов на поверхность $(\theta(r))$. Затем, зная зависимости скорости травления и профиля асферизации $(H=H(r))$ от радиуса детали, рассчитывается сечение формирующей диафрагмы, угол раствора на данном радиусе которой тем больше, чем большее количество материала необходимо снять.

Самым важным преимуществом ионной асферизации над механической является возможность контроля формирующегося профиля $H=H(r)$. Для этого на поверхность аналогичной заготовки (,кукла“ - деталь из того
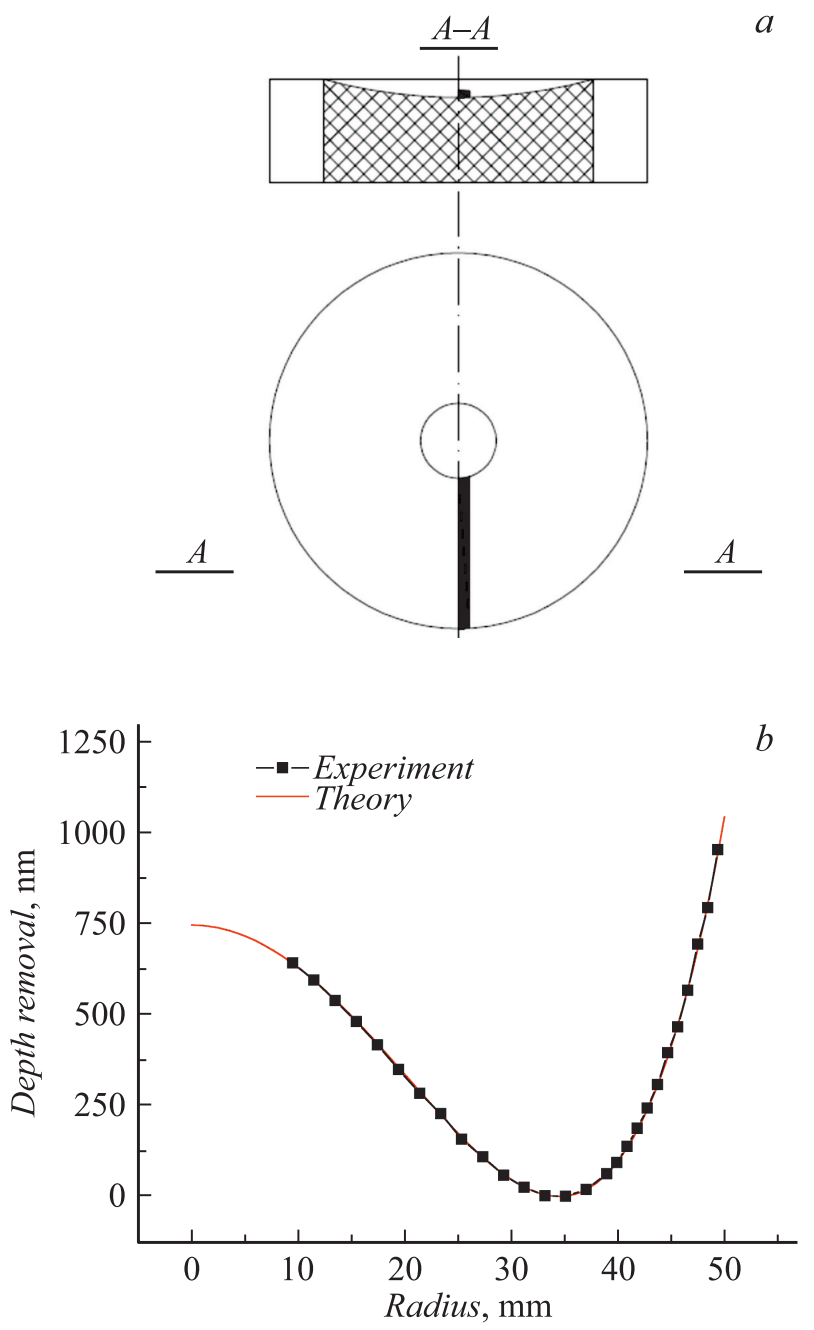

Рис. 9. $a-$ „кукла“ с нанесенной маской для контроля профиля травления; $b-$ сравнение профиля травления (теория и эксперимент).

же материала с тем же радиусом кривизны) наносится маска таким образом, чтобы ее граница проходила вдоль радиуса от центра детали к периферии (рис. 9). Затем через такую маску проводится процедура травления через рассчитанную диафрагму. Время травления (число оборотов) выбирается точно соответствующим реальной процедуре асферизации. Область, которая закрыта маской, не распыляется, в то время как открытая поверхность распыляется в соответствии с формой диафрагмы. Глубина травления на данном радиусе тем больше, чем больше угол раствора диафрагмы. В результате на границе маски формируется ступенька с распределением глубины травления от радиуса, т.е. $H=H_{\exp }(r)$. Высота ступеньки с высокой точностью может быть измерена на интерференционном микроскопе (рис. 9, $b$ ).

В случае, когда $H_{\exp }(r)=H(r)$, проводится процедура осесимметричной обработки, в случае наличия отклонений проводится корректировка формирующей диафрагмы. Пример такого сформированного профиля 
представлен на рис. 9, $b$. Здесь отклонение реального профиля от теоретического составило порядка $1.5 \%$ по параметру PV, PV $=15.9 \mathrm{~nm}, \mathrm{RMS}=3.6 \mathrm{~nm}$. Дальнейшее доведение формы поверхности до субнанометровой точности, если это необходимо, осуществляется по методике коррекции локальных ошибок сфокусированным ионным пучком.

По этой же методике можно проводить процедуру ионно-пучковой полировки поверхности оптического элемента. Отличие заключается в том, что сечение формирующей диафрагмы рассчитывается таким образом, чтобы производить равномерный съем материала вдоль поверхности подложки. В качестве рабочего газа при полировке поверхности могут применяться, помимо $\mathrm{Ar}$, другие инертные газы (Xe, $\mathrm{Ne}$ и др.) в зависимости от конкретной задачи. В частности, в работе [22] именно с применением Хе было получено рекордное значение эффективной шероховатости поверхности для плавленого кварца $\sigma_{\text {eff }}=0.17 \mathrm{~nm}$ в диапазоне пространственных частот $q \in\left[2.5 \cdot 10^{-2}-6.0 \cdot 10^{1} \mu \mathrm{m}^{-1}\right]$. Эта же методика была применена для полировки штрихов дифракционной решетки. Удалось существенно понизить высокочастотную шероховатость, что позволило повысить дифракционную эффективность первого порядка дифракции в несколько раз [28].

По данной методике (при равномерном съеме материала) на поверхности может быть сформирован рисунок маски (ионная литография). Маска может быть нанесена непосредственно на поверхность литографически, либо установлена перед образцом на некотором расстоянии, в этих случаях края рисунка будут либо резкие, либо размытые.

\section{Заключение}

В работе описаны методики обработки оптических поверхностей, в основе которых лежит физическое явление распыления материала под действием ионной бомбардировки. За счет применения пятиосного гониометра, позволяющего проводить сканирование образцом вдоль неподвижного ионного пучка, все методики удалось реализовать на одной установке, оснащенной тремя источниками ускоренных ионов, два - широкоапертурные с квазипараллельным ионным пучком и третий - с фокусировкой ионного пучка. При необходимости произвести заданную операцию, подложка поворачивается в направлении требуемого источника. Кроме того, это позволяет в рамках одного технологического цикла (без развакуумации) проводить несколько операций, например, предварительное удаление слоя окисла при обработке металлов, или предварительную чистку поверхности от пленок углеводородов в кислородной плазме за счет источника КЛАН-103М с накальным катодом.

Весь спектр возможных операций по финишной обработке поверхности удалось разделить на два основных подхода: осесимметричная обработка, осуществляемая при осевом вращении детали без перемещения по остальным осям гониометра, и несимметричная, когда осуществляется сканирование малоразмерным ионным пучком вдоль поверхности детали с поддержанием в каждой точке локальной нормали к поверхности и заданного расстояния источник-образец.

В работе из всего класса задач выделены и подробно описаны три основных направления. Осесимметричная коррекция/асферизация реализуется путем обработки поверхности широкоапертурным источником КЛАН-163М с квазипараллельным ионным пучком. Ток ионов до $200 \mathrm{~mA}$ и диаметр выходной апертуры $150 \mathrm{~mm}$ позволяет проводить обработку деталей с диаметром до $300 \mathrm{~mm}$ со значительным (единицы-десятки $\mu \mathrm{m}$ ) съемом материала.

Ионная полировка может проводиться широкоапертурными источниками с квазипараллельным ионным пучком КЛАН-103М и КЛАН-163М с применением различных инертных газов (в зависимости от материала детали).

Методика коррекции локальных ошибок формы реализована с помощью источника с фокусировкой ионного пучка (выходной пучок $\varnothing 1-15 \mathrm{~mm}$ ). Методика позволяет доводить форму поверхности оптических элементов диаметром до $300 \mathrm{~mm}$ до субнанометровой точности по параметру RMS.

\section{Благодарности}

Работа выполнена с использованием оборудования ЦКП ИФМ РАН, при поддержке Минобрнауки РФ в рамках Соглашения № 075-02-2018-182 (RFMEFI60418X0202).

\section{Конфликт интересов}

Авторы заявляют, что у них нет конфликта интересов.

\section{Список литературы}

[1] Hoffman C., Giallorenzi T.G., Slater L.B. // Appl. Opt. 2015. Vol. 54. N 31. P. 268-F285.

[2] Акопов А.К., Брычихин М.Н., Пластинин Ю.А., Ризванов А.А., Струля И.Л., Эйхорн Я.О., Мальшев И.В., Пестов А.Е., Полковников В.Н., Торопов М.Н., Чхало Н.И. // Космонавтика и ракетостроение. 2014. Т. 78. № 4. С. 77-85.

[3] Wagner Ch., Harned N. // Nature Photon. 2010. Vol. 4. P. 24-26.

[4] Wachulak P.W., Torrisi A., Bartnik A., Wegrzynski L., Fok T., Patron Z., Fiedorowicz H. // Proc. SPIE. 2016. P. 10159.

[5] Weiser M. // Nucl. Instrum. Methods Phys. Res. Sect. B. 2009. Vol. 267. P. 1390-1393.

[6] Arnold T., Bohm G., Fechner R., Meister J., Nickel A., Frost F., Hansel T., Schindler A. // Nucl. Instrum. Methods Phys. Res. Sect. A. 2010. Vol. 616. P. 147-156.

[7] Jiao C., Li S., Xie X., Chen S., Wu D., Kang N. // Appl. Opt. 2010. Vol. 49. N 4. P. 578-585. 
[8] Chkhalo N.I., Kluenkov E.B., Pestov A.E., Polkovnikov V.N., Raskin D.G., Salashchenko N.N., Suslov L.A., Toropov M.N. // Nucl. Instrum. Methods Phys. Res. Sect. A. 2009. Vol. 603. P. $62-65$.

[9] Allen L.N., Romig H.W. // Proc. SPIE. 1990. Vol. 1333. P. 22-33.

[10] Wilson S.R., Reicher D.W., McNeil J.R. // Proc. SPIE. 1988. Vol. 966. P. 74-81.

[11] Eisenberg N.P., Carouby R., Broder J. // Proc. SPIE. 1988. Vol. 1038. P. 279-287.

[12] Xu M., Dai Y., Xie X., Zhou L., Liao W. // Appl. Opt. 2015. Vol. 54. N 27. P. 8055-8061.

[13] Zeuner M., Kiontke S. // Opt. Photon. 2012. Vol. 7. N 2. P. 56-58.

[14] Franz T., Hänsel T. // Optical Fabrication and Testing (21-24 October 2008, Rochester, NY., United States), p. OThC7.

[15] Электронный ресурс. Режим доступа: http://www.opteg.com

[16] Chkhalo N.I., Kaskov I.A., Malyshev I.V., Mikhaylenko M.S., Pestov A.E., Polkovnikov V.N., Salashchenko N.N., Toropov M.N., Zabrodin I.G. // Precision Engineering. 2017. Vol. 48. P. 338-346.

[17] Chkhalo N.I., Malyshev I.V., Pestov A.E., Polkovnikov V.N., Salashchenko N.N., Toropov M.N. // Appl. Opt. 2016. Vol. 55. N 3. P. 619-625.

[18] Chkhalo N.I., Klimov A.Yu., Rogov V.V., Salashchenko N.N., Toropov M.N. // Rev. Sci. Instrum. 2008. Vol. 79. N 3. P. 033107.

[19] Чернышев А.К., Мальиев И.В., Пестов А.Е., Чхало Н.И. // ЖТФ. 2019. Т. 89. Вып. 11. С. 1650-1655.

[20] Зорина М.В., Пестов А.Е., Салащенко Н.Н., Торопов М.Н., Чхало Н.И., Щербаков А.В. // Материалы симпозиума „Нанофизика и наноэлектроника“, г. Нижний Новгород, 12-16 марта 2012. Т. 2. С. 607-608.

[21] Барымева М.М., Вайнер Ю.А., Грибков Б.А., Зорина М.В., Пестов А.Е., Салащенко Н.Н., Храмков Р.А., Чхало Н.И. // Известия РАН. Сер. физ. 2012. Т. 76. № 2. C. 190-195.

[22] Chkhalo N.I., Churin S.A., Pestov A.E., Salashchenko N.N., Vainer Y.A., Zorina M.V. // Opt. Express. 2014. Vol. 22. P. 20094.

[23] Барышева М.М., Вайнер Ю.А., Грибков Б.А., Зорина М.В., Пестов А.Е., Салащенко Н.Н., Струля И.Л., Чхало Н.И. // Поверхность. 2013. № 7. С. 9-13.

[24] Liao W., Dai Y., Xie X., Zhou L. // Appl. Opt. 2014. Vol. 53. N 19. P. 4266-4274.

[25] Chkhalo N.I., Churin S.A., Mikhaylenko M.S., Pestov A.E., Polkovnikov V.N., Salashchenko N.N., Zorina M.V. // Appl. Opt. 2016. Vol. 55. N 6. P. 1249-1256.

[26] Вайнер Ю.А., Зорина М.В., Пестов А.Е., Салащенко Н.Н., Чхало Н.И., Храмков Р.А. // Известия РАН. Сер. физ. 2011. T. 75. № 1. C. 65-67.

[27] Chkhalo N.I., Mikhailenko M.S., Mil'kov A.V., Pestov A.E., Polkovnikov V.N., Salashchenko N.N., Strulya I.L., Zorina M.V., Zuev S.Yu. // Surf. Coat. Technol. 2017. Vol. 311. P. 351-356.

[28] Зорина М.В., Зуев С.Ю., Михайленко М.С., Пестов А.Е., Полковников В.Н., Салащенко Н.Н., Чхало Н.И. // Письма в ЖТФ. 2016. Т. 42. Вып. 16. С. 34-40. 